\title{
Towards Creating an Entrepreneur Competencies Model
}

\section{Leithy WE*}

DBA, Maastricht School of Management Maastricht, The Netherlands

\begin{abstract}
Small and medium-sized enterprises play an important role in developing the economies of nations as literature reveals. Through literature review and SME input, the researchers were able to identify several competencies that contribute to achieving Entrepreneurs Success. The statistical results show two most significant competency groups impacting the Entrepreneurial success: Human Relations Competencies affecting three distinct success dimensions: Ability to attract outside capital, Growth in Revenues and Growth in Customer Base. While the second was the Business and Management Competencies affecting three distinct success parameters: Ability to attract outside capital, Growth in Revenues and Providing Value Added Product or Service towards Creating an Entrepreneur Competencies Model.
\end{abstract}

Keywords: Small and medium-sized enterprises; Competencies; Entrepreneurs success

\section{Introduction}

It is apparent that small and medium-sized enterprises play an important role in developing economies of nations, with a focus on the micro to small enterprises; Nations like Asian giants were able to transfer to their current status in the global economies. Micro and small-sized enterprises are created and fostered by new businessmen that enjoy the vision, the energy and the courage to create a new business, support and grow their businesses. Those Entrepreneurs have certain characteristics, traits and competencies that enable them see the opportunities, are courageous enough to help themselves enter a market full of rivals, and visionary enough to be distinguished from their competitors in a world of aggressive businesses approaches to consumers. It is without a doubt that Entrepreneurial capabilities, knowledge and skills, referred to as competencies, have an important role to pave the road in front of the Entrepreneurs nascent businesses to become successful firms. With Egypt's soaring economic position, growing unemployment rates, reduction in the foreign direct investment and growing population, not only must the country start self-initiatives towards preparing the young generations and encouraging them to start new businesses, creating self-employment opportunities and possibly creating jobs for others, but also improving the money supply and further growing those small enterprises into larger exporters, ultimately helping the economy selfreliance on internal resources and initiatives. Based on the above, it was important to study the key competencies an Entrepreneur in Egypt has to possess in order to become a successful Entrepreneur, and, therefore, allow policy makers create or introduce the required competency training or educational courses into the educational programs either pre- or post-graduation, nonetheless, it is also important to continue with the current encouragement and aiding programs in an effort to promote the idea of self-employment through Entrepreneurship.

\section{Literature Review and Hypotheses}

Competencies are defined as measurable or observable skills, knowledge, abilities and behavior of an individual that would allow him or her to lead a successful life, or work activities. According to Businessdictionary.com, competence or competency can be defined as "A cluster of related abilities, commitments, knowledge, and skills that enable a person (or an organization) to perform effectively in a job or situation. Competence indicates sufficiency of knowledge and skills that enable someone to act in a wide variety of situations. Because each level of responsibility has its own requirements, competence can occur in any period of a person's life or at any stage of his or her career. In the same manor, competencies acquired by Entrepreneurs would help them lead a successful and responsible business and would help them sustain and grow their new businesses once developed. To this end, we believe that previous researches did not define a single set of competencies that would fit for all purposes; in fact, this largely depends on the purpose of use. Therefore, employees required competencies vary significantly, based on the purpose or position within a particular organization. It may also vary from one industry to the other, though; previous work done on competencies for successful Entrepreneurs did not distinguish the required competencies for the different industries in the Entrepreneurial context [1], however, argues that competencies of Entrepreneurs can be defined as base features such as: traits, motives, self-image, skills and knowledge, eventually resulting in creating a new venture, and further survival and growth [2] defines Competencies as people's characteristics that enhance their performance or effectiveness at work. Sanchez argues that those competencies apply to successful managers and in turn he further argues that characteristics apply to successful Entrepreneurs. Sanchez also believes that those characteristics or skills can be trained and developed in Entrepreneurs as well as Managers. According to Wei et al. [3] believe that startup Entrepreneurs despite having a good project and further exerts serious efforts to succeed, they end up in failure. They argue that, there are several reasons behind this failure, yet they concluded that both Entrepreneurial personality and competencies have a very high significance among all reasons.

Many researchers have studied the core competencies that are the key for Entrepreneurs to succeed. Mitchelmore et al. (2008) argue that the term competency holds at least two distinct meanings: behavioral competency, which an individual possesses and demonstrates, and performance-related competency, being a minimum standard of performance. According to Bird [1] competencies necessary to launch a new venture or to plan a new venture may be conceived as "baseline" and highly effective Entrepreneurs are those who go beyond launching and into organizations that survive and grow. Furthermore, Bird debates

*Corresponding author: Leithy WE, DBA, Maastricht School of Management Maastricht, The Netherlands, Tel: +31 43387 0808; E-mail: walid.elleithy@aim-eg.org

Recieved Jun 05, 2017; Accepted July 21, 2017; Published July 28, 2017

Citation: Leithy WE (2017) Towards Creating an Entrepreneur Competencies Model. J Entrepren Organiz Manag 6: 215. doi: 10.4172/2169-026X.1000215

Copyright: ( 2017 Leithy WE. This is an open-access article distributed under the terms of the Creative Commons Attribution License, which permits unrestricted use, distribution, and reproduction in any medium, provided the original author and source are credited. 
that competencies can be acquired through learning, and, therefore, it is important to identify those competencies as an opportunity for learning to improve on the success factor of Entrepreneurs. From the above, it is, therefore, required to split competencies into Entrepreneurial sets of competencies; that would help an Entrepreneur establish a business, but then the sustainability of the business is only achieved through the managerial set of competencies acquired by the Entrepreneur to move to the next level. In between those two sets of competencies, there lies a wider range of competencies including the human relations and communication competencies [4] split out the core competencies into two distinct groups and argued that those are the most important competencies; those were Entrepreneurial competencies, and Managerial Competencies. They have further defined the Entrepreneurial competencies as those necessary to identify and envisage the opportunity, while acting on it to capture and benefit from that. While, they defined the managerial competencies as those required for capturing and utilizing essential resources to pursue business interests and related deeds [5] argue that managerial skills are different from the Entrepreneurial skills. However, for successful Entrepreneurs both sets of skills go hand in hand to ensure a continuously successful growing business. Richardmore et al. (2008) believe that, there is a set of four competency groups that help an enterprise to be established and grow: a) Entrepreneurial Competencies, b) Business and Management Competencies) Human Relations Competencies (HRC), d) Conceptual and relations competencies [3] suggest that there are 17 competencies for successful Entrepreneurs sub-grouped in six groups, they suggest that not all successful Engineers and scientists are as well successful Entrepreneurs; Entrepreneurs are subject to Entrepreneurships opportunity identification and management through gaining from those opportunities. According to Zafar and Khan [6] argues that personal capabilities and leadership skills are factors affecting success experience and knowledge. Zafar and Khan, [6] and Cox and Jennings (1995) believe that decision-making and its innovativeness are key factor towards success [7] further identify opportunity recognition as an important characteristic of Entrepreneurs $[2,8]$ also, state that the enterprises with managers who have high levels of Entrepreneurial competencies have always been successful; they are also characterized for their ability to scan the environment for new opportunities and thus position their ventures towards achieving the required sustainable success that every Entrepreneur strives to achieve. Mitchelmore et al. (2010), propose a clustered set of 4 categories as Female Entrepreneurs Competency model for which all the 41 competencies were grouped.

To conclude, there has been a consensus that a successful Entrepreneur should be visionary enough to see his established firm goals and objective. $\mathrm{He} / \mathrm{she}$ should be able to identify the opportunities and act on to capture those opportunities utilizing a set of Entrepreneurial Competencies. He/she should be able to lead his established enterprise through the path towards success. This requires the Entrepreneur to establish a set of Business and Management Competencies, and in order to do so, he/she should be able to select the right team to help him achieve the goals, which requires the Entrepreneur to have some level of Human Relations Competencies to be developed. Throughout the life of his newly established enterprise, he/she will need to sell his ideas to different stakeholders, which requires him/her to have a certain level of Business Development and Conceptual and Relationship Competencies. To this end, this paper is based on [3] model that comprises 17 unique competencies, clustered into 6 competency groups as well as Mitchelmore et al. proposed set of competencies. Furthermore, the initial list was reviewed with 6 successful Egyptian Entrepreneurs and ended up with a proposed of
5 clusters of Entrepreneurial competencies that to be tested in the Egyptian context as follows:

Entrepreneurial competencies: A set of competencies which would allow the Entrepreneur to identify and capture opportunities in the environment, but would also require innovation and creativity as well as being adaptable and quick in responding to changes. The subset would include 5 distinct competencies as follows: a) Scan environments for opportunities, b) Innovation and Creativity and Idea generation, c) Willingness to take risks, d) Fast and dynamic, f) Adaptability and Proactivity.

Conceptual and relationship competencies: This competency includes a mix of relationship building competencies and personal traits, the subset would include 5 distinct competencies: a) Conceptual and relationship competencies, b) Perseverance, persistence and Desire to succeed, c) Self-confidence and Self-motivation, c) Interpersonal and Oral communication skills, d) Integrity, f) Political competence.

Business development competencies: Once an idea is created, and an opportunity is captured, then comes the importance of idea selling to the partners, investors, co-workers, customers and the public, in order to generate revenues and sustain success. The subset includes 5 distinct competencies as follows: a) Visioning, b) Idea selling, c) Marketing selling, d) Relationship building and networking, f) Formulating and implementing strategies for exploiting opportunities.

Human relations competencies: Those include skills and competencies typically shared by a HR functions and business line functions in larger organizations. They include Leadership, selection, hiring and staffing and employee development and motivation. The subset includes 5 distinct competencies and skills as follows: a) Leadership skills, b) Selection and hiring a diversified team, c) Employee development and Performance Management, d) Motivate others, f) Management skills.

Business and management competencies: The factor includes competencies relating to a typical range of 'business tasks' such as: technical expertise in the relevant business, Management skills, and planning and budgeting skills. The subset includes 5 distinct competencies or skills as follows: a) Technical skills, b) Developing management systems, c) Development of operational systems, d) Planning business activities, f) Problem solving.

Moreover, through the review of literature around Entrepreneurs' success, researchers have not agreed to a single definition of Entrepreneurial success specially when measuring success of newly created enterprises, in fact [6] concluded that there are few reasons for this: a) Nascent firms have difficulty measuring their success in the conventional methods since they lack the standardized accounting measures and performance indicators. b) Comparing different industries and service sectors make it difficult as each acquire unique financial basis and thus incomparable. c) New firms tend not to share or disclose financial results. d) In addition and through interviews with Egyptian SMEs, it shows that the majority of the new businesses operates in a parallel or informal economy, and, therefore, is unwilling to share formal financial results [9] conclude that most researchers go a distance from measuring success in the conventional way and use subjective measurements of success [10] argue that financial results, although easily quantifiable, but are far from being the sole important measure. They suggest that the initial subjective success is measured as a combination of several factors: a) Attaining Entrepreneur's expectations, b) Survival, c) Ability to attract outside capital. They further argue that the value addition and uniqueness of the innovation 
attributes to the success; innovation can apply to either product or service. Therefore this paper suggests using the following criteria to measure Entrepreneurs' success: a) Sustainability of business: According to Hattab [11] a successful new Entrepreneurial venture has an age between 3 and 42 months ( $31 / 2$ years). b) Ability to attract additional outside capital: a successful new venture with promising returns has the ability to attract outside capital. It is, however, not essential for successful Entrepreneurs to grow through acquiring outside additional capital. Rather, some prefer to grow organically, but their ability to attract outside capital is an indication of being a successful new Entrepreneurial venture. According to Stefanovic et al. (2010), access to capital, is one of the factors affecting success. c) Growth (Revenue, Sales, Labor, customer base etc.): according to Perez and Canino [9] the most indicative factor used to measure success was the company's growth, this contributed to a significant $31 \%$ of all indicators in the journals reviewed. Growth is attributed to profit, revenues, manpower or customer base. d) Providing value added product/service: Carlend et al. (2002) argue that the distinguishing factor between an Entrepreneur and small business owner is the innovation and tendency to growth provided as part of the venture strategy.

H1: There is a positive linear relationship between Entrepreneurial Competencies and success of the Entrepreneurs in Egypt.

$\mathrm{H} 2$ : There is a positive linear relationship between Entrepreneurs Conceptual and Relationship Competencies and the success of the Entrepreneurs in Egypt.

H3: There is a positive linear relationship between Entrepreneurs Business Development Competencies and the success of the Entrepreneur in Egypt.

H4: There is a positive linear relationship Entrepreneurs Human Relations Competencies and the success of the Entrepreneur in Egypt.

H5: There is a positive linear relationship Entrepreneurs Business and Management Competencies and the success of the Entrepreneur in Egypt.

\section{Method Participants}

The researchers conducted a comprehensive literature review for previous researches completed in the area of Entrepreneur's Competencies required for successful startup of business, and the area of success measurement of nascent business. A semi-structured interview of 7 SMEs followed the literature review stage, 6 of those were successful Entrepreneurs, while the seventh had discontinued the business as he had experienced difficulties. All 7 SMEs contributed to the enhancement of the literature reviewed proposed model to match the Egyptian market. During the early stage of this research, a qualitative approach was followed through the SMEs interviews to enable better understanding of the subject. Later after landing to a proposed model, and development of research hypothesis, a quantitative approach was followed through the dissemination of the survey questionnaire, analyzing the results and concluding the statistical outcomes to test the relationship between the variables. According to Egyptian Junior Businessmen association based in Cairo-Maadi, there are circa 600 business executives and Entrepreneurs registered on the active membership of the association, and accordingly a convenient sample of 86 were selected for the dissemination of the survey questionnaire, yet only 42 responded to the survey, with 2 incomplete surveys, resulting in a response rate of $49 \%$, and complete survey respondents of $47 \%$ of the sample.

\section{Procedure}

Based on the type of data of this research, the Logistic linear analysis is used to modify the model. The dependent variable, Entrepreneur's success and all its dimensions, are binary variables. If the dependent variable $(\mathrm{Y})$, is one of the binary response or dichotomous variable, such as Male/Female, Yes/No, Success/Fail, Present/Absent or Smoking/ Nonsmoking, logistic regression can be used to describe its relationship with several predictor variables, $\mathrm{X} 1, \mathrm{X} 2, \ldots, \mathrm{X}-\mathrm{k}$ and an (adjusted) odds ratio can be estimated [12] for a binary response, $y$, the expected value of $y, E(y)=\pi$, where $\pi$ denotes Probability $P(y=1)$. The log model is:

Equation: Logistics Model

$$
\pi=\frac{\exp \left(\mathrm{B}_{\mathrm{o}}+\mathrm{B}_{1} \mathrm{x}_{1}+\ldots+\mathrm{B}_{\mathrm{i}} \mathrm{x}_{\mathrm{i}}\right)}{1+\exp \left(\mathrm{B}_{\mathrm{o}}+\mathrm{B}_{1} \mathrm{x}_{1}+\ldots+\mathrm{B}_{\mathrm{i}} \mathrm{x}_{\mathrm{i}}\right)}
$$

Through algebraic manipulation the above formula can be represented as follows:

$$
\ln \left[\frac{\pi}{1-\pi}\right]=\mathrm{B}_{\mathrm{o}}+\mathrm{B}_{1} \mathrm{x}_{1}+\ldots+\mathrm{B}_{\mathrm{i}} \mathrm{x}_{\mathrm{i}}
$$

Notice that although the regression model is linear on the right side, the left side is a nonlinear function of the response variable $\pi$.

Also, since $\pi=P(y=1$ or success $)$, then $1-\pi=P(y=0$ or failure $)$.

The ratio $\frac{\pi}{1-\pi}=\frac{\mathrm{P}(\mathrm{y}=1)}{\mathrm{P}(\mathrm{y}=0)}$ is known as the odds of the event $\mathrm{y}=1$ or success occurring.

Six distinct logistic regression analyses were conducted in this study; one distinct regression for each of the five dimensions and a collective regression at the end [13-16]. To reach the best model that fits the data, the backward stepwise method was used to reach the set of all significant variables $[17,18]$.

\section{Results}

For the Business Sustainability is one of the indicators of the success of the Entrepreneur in Egypt, the results shows that all the proposed independent variables of this study are insignificant (Table 1).

Only the constant is significant which means that to exceed three years of business is 3.444 times the likelihood of not exceeding the three years.

For the Ability to Attract outside Capital, The results show that there is only one significant variable which is the Human Relations Competencies (H.R.C.) affecting the ability to attract outside capital (Table 2).

The exp (B) of the H.R.C. is 3.585. This implies that the odds of attracting outside capital for a person with one unit higher in the H.R.C. is 3.585 times the odds of attracting outside capital for a person with one unit less given that all the other factors are fixed at the same level. In other words, a person with a higher level of competency in Human Relations is more likely to attract outside capital. Meanwhile, the pseudo R2 is $15.6 \%$. This R2 is very similar to the adjusted R2 in the multiple regressions (Table 3 ).

For the Revenue Growth, the results show that only one variable is significant (Table 4).

A person with a higher level of Human Relation Competencies is more likely to have a revenue growth. The odds of having a revenue growth for a person one level higher in H.R.C. are 5.9 times a person 


\begin{tabular}{|c|c|c|c|c|c|}
\hline Business Sustainability Model Variables & B & S.E. & Wald & df & Sig. \\
\hline Constant & 1.237 & 0.379 & 10.669 & 1 \\
\hline
\end{tabular}

Table 1: Business Sustainability Model Variables.

\begin{tabular}{|c|c|c|c|c|c|}
\hline Ability to Attract Outside Capital' Model Variables & B & S.E. & Wald & df & Sig. \\
\hline Human Relations Competencies & 1.277 & 0.628 & 4.139 & 1 \\
\hline Constant & 2.561 & 1.155 & 4.919 & 0.042 \\
\hline
\end{tabular}

Table 2: Ability to Attract Outside Capital' Model Variables.

\begin{tabular}{|c|c|c|}
\hline $\mathbf{- 2}$ Log likelihood & Cox \& Snell R Square & Nagelkerke R Square \\
\hline $49.621 \mathrm{~b}$ & 0.116 & 0.156 \\
\hline
\end{tabular}

Table 3: Pseudo R Square for Model 2.

\begin{tabular}{|c|c|c|c|c|c|}
\hline Revenue Growth 'Model Variables & B & S.E. & Wald & df & Sig. \\
\hline Human Relations Competencies & 1.778 & 0.706 & 6.345 & 1 \\
\hline Constant & -9.95 & 4.317 & 5.313 & 1 \\
\hline
\end{tabular}

Table 4: Revenue Growth' Model Variables.

with a lower level in the H.R.C. While the pseudo R2 is $26.5 \%$. This implies that $26.5 \%$ of the variation in the revenue growth is explained by the human relations competencies (Table 5 ).

Meanwhile, the results show that that there are three independent variables influencing the customer base growth:

CRC: If the Conceptual Relationship Competencies are higher with one level so it is more likely not to have a customer base growth,

EC: The same applies to the Entrepreneurial Competencies; if the Entrepreneurial competencies are higher with one level; so it is more likely not to have a customer base growth. 3- H.R.C. - On the contrary, a person with higher Human Relations Competencies is more likely to have a customer base growth (Table 6).

While the pseudo R2 is $42.9 \%$. This implies that $42.9 \%$ of the variation in the customer base growth is explained by Conceptual Relationship Competencies, Human Relations Competencies and Entrepreneurial Competencies (Table 7).

As for Providing Value Added Service or Product as one of the indicators of the success of the Entrepreneur in Egypt, the results show that 2 variables are significant at $5 \%$ level of significance. The Business and Management Competencies (BMC) and Gender are both affecting the success of the Value added product or service presentation by the Entrepreneur.

If the BMC level increases by one unit then the likelihood to succeed in presenting Value added product or service is higher than a person with one level lower. On the other hand, being male increases the likelihood of succeeding in presenting Value added product or service.

It is evident that the SE for Gender is very high; this is attributed to the fact that most respondents are males (Table 8). The pseudo $\mathrm{R} 2$ is $31.7 \%$. This implies that $31.7 \%$ of the variation in the value added product or service is explained by Business and Management competencies and Gender (Table 9).

Finally, the collective logistic regression model shows that that the Level of Education and the Human Relations Competencies (HRC) are the only significant variables affecting the aggregated Entrepreneur's success as explained by this model. If the Human Relations Competencies level increase it is more likely to succeed (Table 10).
The same applies to the level of education; an Entrepreneur with a higher level of education is more likely to succeed. The pseudo R2 is equal to $30 \%$. This implies that $30 \%$ of the variation in the total Entrepreneur's success is explained by Human Relations Competencies and Level of Education (Table 11).

\section{Discussion}

This research had a prime objective of identifying the key competencies that are required by Egyptian Entrepreneurs allowing them create a successful enterprise. Through previous global work on Entrepreneur's success in different parts around the world, and further enhancements through semi-structured interviews of SMEs in Egypt, the researcher was able to formulate a major question to the research which is: What are the Key Entrepreneurs' competencies affecting Entrepreneurship success in Egypt? Those competencies were then re-grouped in accordance with previous work and SME feedback into 5 categories: Entrepreneurial Competencies, Conceptual and Relationship Competencies, Business Development Competencies, Human Relations Competencies and Business and Management Competencies. The researcher then formulated minor questions to further test the effect of those individual Competencies over the Entrepreneur's Success dimensions and further testing the demographics effect on each of those relationships. While considering the limitations of the research, and the small sample size as well as the limited respondents count, it was verified that the most significant competency group at a confidence level $90 \%$ impacting the Egyptian Entrepreneurial success were the Human Relations Competencies affecting Three of the five distinct success dimensions of Egyptian Entrepreneurs contributing to an overall success. Those distinct success parameters were: 1) Ability to attract outside capital, 2) Growth in Revenues and 3) Growth in Customer Base. At the same confidence level of $90 \%$, the researcher found another significant Competency affecting Egyptian Entrepreneur's success was the Business \& Management Competencies affecting Three of Five distinct success parameters: 1) Ability to attract outside capital, 2) Growth in Revenues and 3) Providing Value Added Product or Service.

As indicated in the introduction to this research, one of the research goals was to be able to provide some outlined focus areas to NGOs and policy makers, in effort to promote Entrepreneurship and equip youth Entrepreneurs with necessary competencies, allowing them create 
Citation: Leithy WE (2017) Towards Creating an Entrepreneur Competencies Model. J Entrepren Organiz Manag 6: 215. doi: 10.4172/2169026X.1000215

Page 5 of 6

\begin{tabular}{|c|c|c|c|c|c|c|}
\hline-2 Log likelihood & \multicolumn{3}{|c|}{ Cox \& Snell R Square } & \multicolumn{3}{|c|}{ Nagelkerke R Square } \\
\hline $38.964 b$ & \multicolumn{3}{|c|}{.183} & \multicolumn{3}{|c|}{.265} \\
\hline \multicolumn{7}{|c|}{ Table 5: Pseudo R Square for Model 3.} \\
\hline Customer Base Growth' Model Variables & B & S.E. & Wald & df & Sig. & $\operatorname{Exp}(B)$ \\
\hline Conceptual Relationship Competencies & -2.314 & 1.439 & 2.586 & 1 & .108 & .099 \\
\hline Human Relations Competencies & 3.807 & 1.393 & 7.471 & 1 & .006 & 45.020 \\
\hline Entrepreneurial Competencies & -1.814 & 1.107 & 2.684 & 1 & .101 & .163 \\
\hline Constant & 4.238 & 6.961 & .371 & 1 & .543 & 69.295 \\
\hline
\end{tabular}

Table 6: Customer Base Growth' Model Variables.

\begin{tabular}{|c|c|c|}
\hline $\mathbf{- 2}$ Log likelihood & Cox \& Snell R Square & Nagelkerke R Square \\
\hline $27.380 \mathrm{~b}$ & 0.271 & 0.429 \\
\hline
\end{tabular}

Table 7: Pseudo R Square for Model 4.

\begin{tabular}{|c|c|c|c|c|c|}
\hline Value Added product or Service Presentation' Model Variables. & B & S.E. & Wald & df & Sig. \\
\hline Business and Management Competencies & 1.604 & 0.717 & 5.014 & 1 \\
\hline Gender & 20.241 & 17639.28 & 0.025 & 4.975 \\
\hline Constant & -8.925 & 4.247 & 4.416 & 1 \\
\hline
\end{tabular}

Table 8: Value Added product or Service Presentation' Model Variables.

\begin{tabular}{|c|c|c|}
\hline $\mathbf{- 2}$ Log likelihood & Cox \& Snell R Square & Nagelkerke R Square \\
\hline $38.729 a$ & 0.224 & 0.317 \\
\hline
\end{tabular}

Table 9: Pseudo R Square for Model 5.

\begin{tabular}{|c|c|c|c|c|c|}
\hline Entrepreneur's Success' Model Variables & B & S.E. & Wald & df & Sig. \\
\hline Constant & -3.947 & 5.393 & 0.536 & 1 & 0.464 \\
\hline Human Relations Competencies & 1.422 & 0.686 & 4.299 & 0.019 \\
\hline Level Of Education & 1.614 & 0.875 & 3.406 & 1 \\
\hline Constant & -8.461 & 4.216 & 4.027 & 0.038 \\
\hline
\end{tabular}

Table 10: Entrepreneur's Success' Model Variables.

\begin{tabular}{|c|c|c|}
\hline $\mathbf{- 2}$ Log likelihood & Cox \& Snell R Square & Nagelkerke R Square \\
\hline $33.799 \mathrm{c}$ & 0.199 & 0.303 \\
\hline
\end{tabular}

Table 11: Pseudo R Square for Model 6.

successful businesses and avail employment opportunities, accordingly research recommendations can be summarized as follows:

Policy makers need to adopt a strategy by which they further prepare young generations at schools with the necessary competencies highlighted in this research (See point 5 below).

Egyptian policy makers to study the successful path China had gone through, to improve Entrepreneurs propensity to success; furthermore, they need to set a plan to implement applicable programs to Egypt through government sponsored programs financed by businessmen and NGOs.

Government to sponsor training programs addressing Key successful Entrepreneur's Competencies, and encourage NGOs to role out those programs and be financed primarily through businesses CSR activities. Those programs should be widely publicized and be available to younger generations.

Government to adjust applicable regulations in a way to enforce Corporate CSR programs to be directed to certain development areas; such as New Entrepreneur's Competencies training programs; it is also suggested that law would link the amount spent on CSR to the firm's profits.

Suggested programs to cover the following key competencies as seen through this research.
Human Relations Competencies: those would include: Leadership skills, Selection and hiring a diversified team, Employee development and Performance Management, Motivate others and the different Management skills.

Business and Management Competencies; those would include: Technical skills, Developing management systems, Development of operational systems, Planning business activities, Problem Solving.

The Research suggests that there is a set of other possible Competencies contributing to the success of Egyptian Entrepreneurs in Egypt; those would need to be further explored. The research had only looked into the greater Cairo area for Entrepreneurial activities, future researches would need to explore beyond Cairo, and include other major cities were Entrepreneurs can be found; examples would include Alexandria, Port Said, Damietta, and other rural areas in upper and lower Egypt. The research survey characteristics show that the respondents were all highly educated, for future work, the sample should as well included less fortunate Entrepreneurs who were not able to acquire higher degrees, or better opportunities of education.

\section{References}

1. Bird B (1988) Implementing Entrepreneurial ideas: The case for intention Academy of Management Review 13: 442-453. 
Citation: Leithy WE (2017) Towards Creating an Entrepreneur Competencies Model. J Entrepren Organiz Manag 6: 215. doi: 10.4172/2169026X.1000215

2. Sanchez J (2012) the influence of Entrepreneurial competencies on small firm performance. Revista Latinoamericana de Psicolog'a.

3. Wei F, Ning Z, Xuejun C, Jianchum F (2012) "Overseas Returnees' Entrepreneurial Competency and Personality Research." Canadian Social Science 8: 186-194.

4. Chandler GN, Hanks SH (1994) Founder competence, the environment, and venture performance, Entrepreneurship Theory and Practice 18: 77-89.

5. Lerner M, Almor T (2002) Relationships among strategic capabilities and the performance of Women owned small ventures. Journal of Small Business Management 40: 109-125.

6. Zafar S, Khan IM (2013) Examining Factors of Entrepreneurial Success: Culture, Gender, Education, Family, Self-Perception. Journal of Poverty, Investment and Development 2: 37-48.

7. Hodgetts RM, Kuratko DF (1992) Effective Small Business Management, (4th edn.), Harcourt Brace Jovanovich, San Diego, FL.

8. Covin J, Miles M (2006) Corporate Entrepreneurship and the pursuit of competitive advantage, pp: 47-63.

9. Perez EH, Canino RM (2009) The Importance of the Entrepreneur's Perception of Ò Success. Review of International Comparative Management 10: 990-1010.
10. Stuart R, Abetti PA (1987) Start-up ventures: Towards the prediction of initial success. Journal of Business Venturing 2: 215-230.

11. Hattab H (2013) Global Entrepreneurship Monitor. Egypt 2012

12. Agresti A (2002) Categorical Data Analysis. John Wiley \& Sons 359: 655-688.

13. Benzing C, Chu HM, Kara O (2009) Entrepreneurs in Turkey: a factor analysis of motivations, success factors, and problems. Journal of Small Business Management 47: 58-91.

14. Egyptian Junior Businessmen Association

15. Hinton PR, Brownlow C, McMurray I. (2004) SPSS Explained East Sussex England: Routledge Inc.

16. Siwan M, Jennifer R (2010) "Entrepreneurial competencies: a literature review and development agenda". International Journal of Entrepreneurial Behaviour \& Research 16: 92-111.

17. Robichaud Y, Cachon JC, Haq R (2010) Motives, Success Factors, and Barriers among Canadian Female Entrepreneurs: The Case of Greater Sudbury. Entrepreneurial Practice Review 1: 36-65.

18. Tavakol M, Dennick R (2011) Making sense of Cronbach's alpha. International Journal of Medical Education 2: 53-55. 